\title{
RELEITURA CRÍTICA (SOCIAL E POLÍTICA) DO PRINCÍPIO DA JUSTIÇA EM BIOÉTICA
}

\section{CRITICAL (SOCIAL AND POLITICAL) RECONCEPTUALIZATION OF THE PRINCIPLE OF JUSTICE IN BIOETHICS}

\author{
Volnei Garrafa \\ Camilo Manchola-Castillo
}

\section{RESUMO}

Este artigo apresenta uma releitura crítica do princípio da justiça em Bioética, que pressupõe ir além do usual legalismo jurídico. Propõe-se fazer uma leitura social e política do princípio a partir da relação existente entre Bioética e Direitos Humanos, legitimada suficientemente pela aprovação, por unanimidade, da Declaração Universal sobre Bioética e Direitos Humanos da Unesco, em 2005. A dimensão social da justiça em Bioética é argumentada por meio da discussão da equidade e do tema meio ambiente; e a dimensão política, por sua vez, por meio da discussão das seguintes categorias: empoderamento, emancipação e libertação. Conclui-se que uma releitura crítica do princípio da justiça em Bioética é necessária para a construção de uma Bioética justa, democrática e cidadã.

Palavras-chaves: Bioética. Conceito de Justiça. Inclusão social. Política.

\section{ABSTRACT}

This article presents a critical reconceptualization of the principle of justice in bioethics, which implies going beyond the usual juridical legalism. A social and political reading of the principle is proposed, based on the existing relationship between bioethics and human rights, sufficiently legitimized by the unanimous approval of the UNESCO Universal Declaration on Bioethics and Human Rights in 2005. The social dimension of justice in bioethics is tackled through the discussion of equity and the theme of the environment, and the political dimension, through the discussion of the categories empowerment, emancipation, and liberation. We conclude that a critical reconceptualization 
of the principle of justice in bioethics is necessary for the construction of a just, democratic and citizen bioethics.

Keywords: Bioethics. Concept of Justice. Social Inclusion. Politics.

\section{INTRODUÇÃo}

Desde os primórdios da bioética, no início dos anos 1970, o Princípio da Justiça é um de seus pilares básicos de sustentação conceitual e prática. Juntamente com os princípios da autonomia, beneficência e não-maleficência, contribuiu para a divulgação e consolidação da bioética no contexto internacional das décadas de 1980 e 1990. Sua interpretação, aprofundamento e análise mereceram a atenção de estudiosos de diferentes partes do mundo, em todos estes pouco mais de 40 anos de história da disciplina.

No final do século XX, no entanto, começaram a surgir críticas de diferentes lugares com relação ao presumível universalismo dos chamados “Quatro Princípios de Georgetown”, então já conhecidos e reconhecidos internacionalmente como uma teoria ética própria: o Principialismo. A referida corrente de pensamento bioético tem hoje como base de sua sustentação conceitual a "teoria da moralidade comum" introduzida na 4⿳亠丷厂 edição da obra (1994) pelos seus autores Tom Beauchamp e James Childress e aprofundada nas edições subsequentes do livro Principles of Biomedical Ethics (BEAUCHAMP; CHILDRESS, 1994, 2002, 2009, 2013). Além dos argumentos relacionados com a necessidade de contextualização dos conflitos morais à realidade concreta onde os mesmos ocorrem e, levando ainda em consideração os referenciais culturais de cada país ou região geopolítica, vozes acadêmicas críticas passaram a centrar análises principalmente no super-dimensionamento do princípio da autonomia frente aos outros três, apontando, também, para as possibilidades de antagonismos operacionais entre os próprios princípios, principalmente entre a autonomia e a justiça (CLOUSER ; GERT, 1990; HOLM, 1995; LEPARGNEUR, 1996; GARRAFA; DINIZ; MATOS, 1999).

É necessário registrar que a fundamentação individualista anglo-saxônica original do Principialismo, na sua aplicação cotidiana, acabou por 
configurar um quadro de maximização de temas de interesses individual e privado com relação aos coletivos e de amplitude pública (GARRAFA, 2005). Aliás, esta tendência de privilegiar as questões individuais/privadas em detrimento das coletivas/públicas, já estava contida no texto do próprio Belmont Report, desenvolvido nos Estados Unidos entre os anos 1974 e 1978, que conferia ao Princípio da Justiça as seguintes cinco características básicas: Para cada pessoa uma porção igual; Para cada pessoa de acordo com as necessidades individuais; Para cada pessoa de acordo com seu esforço; Para cada pessoa de acordo com sua contribuição social; Para cada pessoa de acordo com o mérito (BELMONT REPORT, 1978). A estas características, Beauchamp \& Childress (1979) acrescentaram uma sexta: Para cada pessoa de acordo com as trocas livres de mercado. Todas as seis categorias propostas, portanto, direcionam-se aos campos das liberdades e necessidades individuais, alijando completamente os referenciais da justiça como uma necessidade social componente do campo dos direitos humanos universais, objeto central do presente texto.

\section{BIOÉTICA, JUSTIÇA E DIREITOS HUMANOS}

A maximização da importância do princípio da autonomia, como já foi dito acima, transformou o principio de justiça, na prática bioética do dia-a-dia, em um mero coadjuvante - embora sempre lembrado e levado em consideração - mas de importância relativa na teoria principialista; o individual sufocou o coletivo, o "eu" empurrou o "nós" para uma posição secundária (GARRAFA, 2005). De acordo com o referido estudo: "a teoria principialista se mostrou insuficiente para desvelar, entender e intervir nas macro-questões sócio-econômicas e sanitárias, coletivas e persistentes, relacionadas principalmente com as populações menos favorecidas e sabidamente majoritárias do planeta" (GARRAFA, 2012, p. 752).

0 Princípio da Justiça terminou significando para o principialismo clássico - na prática concreta - proporcionalmente o que a "Promoção da Saúde" nos seus primórdios representava no contexto sanitário mundial dos já distantes anos 1960 para a então chamada "medicina social": algo teórico, de presença indispensável, mas pouco palpável sob o ponto de 
vista prático, onde cabiam todos os demais problemas não absorvidos nas outras quatro categorias do contexto preventivo seguido na época - proteção específica, diagnóstico precoce, limitação do dano e reabilitação (ou a autonomia, beneficência e não-maleficência, no contexto da presente discussão...), considerados principais.

Assim, do mesmo modo que com o passar do tempo foi construída uma sólida fundamentação teórica e operacional atualmente existente para o campo da Promoção da Saúde, hoje em dia é indispensável repensar o Princípio da Justiça em bioética, a partir de outros referenciais que estejam situados para mais além das contradições simplistas e diretas representadas pelo conflito entre bem e mal, justo e injusto, certo e errado e, especialmente, entre inclusão e exclusão... E para isto, é essencial que tais referenciais sejam ampliados com relação à fundamentação anglo-saxônica individualista seguida pela corrente teórica principialista.

0 objetivo do presente estudo, portanto, é procurar diferenciar, sem separar, a visão de justiça dos limites do exclusivo legalismo jurídico, objetivando ampliação e aprofundamento da epistemologia do tema na relação existente entre o campo da bioética e as questões relacionadas com a justiça como direito humano. A justiça, como princípio indispensável de uma bioética pluralista, laica e direcionada aos direitos humanos universais, requer mais fortemente um caráter de legitimação moral do que de legalismo jurídico.

Neste sentido, preferencialmente a obrigações ou deveres, falaremos em direitos - direitos sociais, direitos cidadãos, direitos das gerações futuras...- na busca da (re)construção de uma ética democrática ampliada e, primordialmente pública e coletiva, comprometida com questões indispensáveis à sobrevivência digna das maiorias populacionais necessitadas do planeta. Afinal de contas, esta foi uma das razões para a criação, consolidação e existência da própria bioética como novo território do conhecimento inter e transdisciplinar, necessário à oportunização de novas leituras e ao enfrentamento dos problemas éticos persistentes e emergentes constatados nas sociedades contemporâneas. Nesta linha de ideias, temas como a relação entre a ética e a política, ou como a equidade, justiça ambiental, empoderamento, libertação e outros, serão incorporados ao corpo da discussão. 
A bioética, que nesse texto trata de aprofundar o conceito de Princípio da Justiça e sua relação com ela, é compreendida como a ética do conhecimento não somente com relação às questões biomédicas e sanitárias, mas, acima de tudo, direcionada para a própria vida humana, ambiental e planetária, atual e futura. Trata-se, portanto, de uma ética com um enfoque transdisciplinar do conhecimento, que permite a junção da crítica atualizada dos fatos que estão acontecendo, com a praticidade e experiências já desenvolvidas pelas ciências aplicadas, objetivando, em última instância, um futuro melhor para as gerações que estão por vir.

Assim, a proposta conceitual para o desenvolvimento deste tópico terá uma visão particular de justiça, especialmente enfocada nos aspectos político-sociais, em grande parte esquecidos pelas abordagens tradicionalmente encontradas na maioria dos textos acadêmicos publicados pela bioética internacional (GARRAFA; KOTTOW; SAADA, 2006).

É indispensável precisar, também, que na nova agenda redesenhada com a Declaração Universal sobre Bioética e Direitos Humanos da UNESCO, em 2005, a justiça - incorporada pelos temas dos direitos humanos universais e do respeito à dignidade humana - passa a estar além de qualquer outra referência conceitual no contexto histórico da bioética (UNESCO, 2005).

\section{A BIOÉTICA DO SÉCULO XXI: UMA FERRAMENTA DE IN- CLUSÃO SOCIAL}

Com a homologação da Declaração Universal sobre Bioética e Direitos Humanos da Unesco, a agenda bioética do século XXI foi definitivamente ampliada; e com ela, especificamente, o tema da Justiça passou a requerer, também, novas interpretações. A nova agenda se projeta para além das questões biotecnocientíficas, às quais havia sido reduzida nos anos 1980 e 1990, com base nos interesses unilaterais de algumas nações industrializadas, especialmente na relação dos profissionais de saúde com seus pacientes e dos patrocinadores de pesquisas clínicas com os sujeitos das mesmas. A nova referência conceitual da disciplina proporciona uma abertura mais rica de possibilidades de atuação, incorporando - além dos 
tradicionais temas biomédicos e biotecnológicos, já mencionados - as questões sanitárias, sociais e ambientais, fator indispensável para a consecução de uma bioética realmente comprometida com as diferentes situações relacionadas com a qualidade da vida humana em seu sentido amplo.

Este conceito diferenciado de bioética ampliou substancialmente seu campo de atuação, oxigenando-a e politizando-a, ao incorporar temas de interesse direto das nações periféricas do hemisfério sul do mundo, como a inclusão social, a universalidade de acesso das pessoas a cuidados de saúde de boa qualidade e a medicamentos essenciais, a proteção da biodiversidade, um respeito maior por temas ambientais como o direito ao acesso a água potável e ar puro, o combate à violência em todos seus níveis, o direito à alfabetização, o compartilhamento dos benefícios decorrentes dos avanços científico-tecnológicos...

As conquistas observadas no mundo contemporâneo, como consequência do desenvolvimento científico e tecnológico, do ponto de vista da ética da responsabilidade pública, são muito frágeis. Segundo Jonas (1990), frente às profundas contradições que a humanidade (e os países...) se vê obrigada a enfrentar, é necessário que a racionalidade ética comece a caminhar com a mesma velocidade que o progresso técnico e científico. A filosofia pode dizer várias coisas concretas: que tipos de vida são melhores que outros, que coisas trazem benefícios ou prejuízos. É conveniente recordar, também, que o progresso moral coletivo existe e se evidencia de três formas: a) mediante as legislações dos Estados modernos; b) em certos valores que são incorporados aos códigos das leis; mas, principalmente: c) nos comportamentos públicos (JONAS, 1990).

Existe uma tradição nas sociedades ocidentais segundo a qual certos setores hegemônicos estabelecem e determinam unilateralmente os direitos dos indivíduos e os rumos a serem seguidos. Essa tradição, que está mudando, mas em proporção ainda muito lenta e insuficiente, não somente gera desigualdades profundas, como também limita e condiciona o exercício dos mesmos direitos (individuais e coletivos).

0 direito, que é elemento básico da ordem da cidadania, não deve ser atribuído; pelo contrário, o princípio ético-político que rege a noção mais elementar do direito é o que provém da própria existência humana, uma vez que quando a pessoa nasce, já se configuram direitos. Mais do que 
configurados, estes direitos devem estar acessíveis e materializáveis para que se alcance a verdadeira cidadania (GARRAFA; OSELKA; DINIZ, 1997).

Neste sentido, a bioética tem a oferecer de seu rico instrumental teórico-prático, entre outras ferramentas, a proposta de comitês de bioética institucionais, hospitalares, profissionais, no campo da pesquisa científica e outros: pluralistas no que diz respeito à moralidade de seus membros; e multidisciplinares relativamente às formações profissionais dos mesmos - incluindo também e em proporção representativa - pessoas sem formação acadêmica, da população. Mais importante ainda do que os comitês que tratam de questões específicas do campo biomédico, a disciplina pode proporcionar aos diferentes países do mundo, Comitês ou Conselhos Nacionais de Bioética, que devem funcionar como colegiados consultivos, de amplitude nacional e com capacidade comprovada para se responsabilizar por reflexões em profundidade sobre temas morais que perpassam o contexto societário das nações que os sediam (GARRAFA; TEN HAVE, 2010).

\section{A DIMENSÃO SOCIAL DO PRINCÍPIO DA JUSTIÇA}

São muitos os elementos que poderiam ser mencionados para uma análise conceitual e relacional entre o Princípio bioético da Justiça e o direito das pessoas e comunidades ao acesso a uma vida digna e com qualidade. O estudo do Princípio da Justiça em bioética, de acordo com o enfoque macro aqui definido, portanto, não pode prescindir de uma aproximação com o tema dos direitos humanos e da inclusão social. A inclusão social vem recebendo suporte teórico de diferentes conceitos e denominações no transcurso dos tempos, com interpretações também diversas.

0 que proporciona humanidade aos seres biologicamente reconhecidos como humanos é consequência de um processo coletivo que se consubstancia na produção e reprodução contínuas dos significados atribuídos às práticas sociais. Neste sentido, a proposta de politização da bioética aqui defendida tem relação com o pressuposto de que a ação social politicamente comprometida é aquela com capacidade de transformar a práxis social (GARRAFA, 2008). 
A globalização da economia mundial, ao contrário de diminuir a distância entre ricos e pobres do planeta, embruteceu ainda mais as contradições, acentuando os problemas já existentes. Nos países em desenvolvimento (periféricos), a maioria da população segue lutando pela obtenção de condições mínimas de sobrevivência e dignidade. Enquanto isso, a partir do conceito de ética aplicada proposto e implementado pelos países ricos (centrais), é crescente o processo de despolitização dos conflitos morais, por mais graves que estes sejam.

A estratégia de pontuar a discussão a respeito da inclusão e equidade social como referência na agenda das discussões éticas, contribui para aproximar este campo da equidade. A bioética inclusiva e social, para ser efetiva, além da disposição, persistência e preparo acadêmico por parte do sujeito interessado em seu desenvolvimento, exige uma espécie de militância programática e coerência histórica, seja este sujeito um estudante, trabalhador da saúde, membro de um comitê de ética ou pesquisador. A inclusão da agenda social na bioética é uma forma concreta de contribuição para a construção da justiça social, uma vez que se considera a bioética, neste contexto, um novo instrumento, uma nova ferramenta teórica e metodológica com suficiente vigor e atualidade para atuar concretamente na construção da cidadania e da verdadeira democracia, na luta contra toda e qualquer forma de exclusão social.

A visibilidade da discussão sobre equidade, no mundo ocidental, começou aproximadamente na metade do século passado. Os movimentos sociais, especificamente os que reivindicam causas relativas à discriminação por razões de raça ou de gênero, foram seus principais predecessores. Depois de um forte início, nos anos 1950 e 1960, diminuiu um pouco sua expressão nos anos seguintes. Mais recentemente, com outra roupagem, tem sido reanimado particularmente pelas discussões no campo sanitário e da justiça. Isto pode ser visto, por exemplo, nos encontros promovidos pela Organização Mundial da Saúde sobre a revisão de metas acerca da proposta do programa "Saúde para todos no ano 2000", nas últimas décadas do século passado e, mais recentemente, com relação aos novos "Indicadores de Saúde para o Milênio" e aos "Determinantes Sociais de Saúde". Nestes movimentos, o conceito de equidade foi retomado com 
vigor, passando a significar uma palavra especial e chave no contexto da concepção de qualidade de vida.

Basicamente, equidade significa a disposição de reconhecer igualmente o direito de cada um a partir de suas diferenças. Tratar indistinta e igualmente a desiguais e iguais, é desigualdade. Os desiguais devem ser tratados desigualmente, exatamente levando-se em consideração aquilo que os desiguala. Justiça, neste caso, não é atribuir o mesmo a todos, como se todos fossem equivalentes. Justiça é tratar de modo diferenciado pessoas que não são iguais (RAWLS, 2002).

A igualdade é a consequência desejada da equidade, sendo esta o ponto de partida para aquela. É por meio do reconhecimento das diferenças e necessidades diversas dos sujeitos sociais que se pode alcançar a igualdade. A igualdade não é mais um ponto de partida ideológico e neutral que tendia a anular as diferenças; é o ponto de chegada da justiça social, referencial dos direitos humanos na busca pelo aperfeiçoamento da cidadania (GARRAFA; OSELKA ; DINIZ, 1997).

A equidade, então, é o indicador justo que deve guiar o processo de tomada de decisões éticas, por exemplo, com relação ao tema da alocação de recursos (geralmente insuficientes...) para programas públicos. É somente através deste indicador, associado aos referenciais da responsabilidade (individual e pública) e da justiça, que se pode fazer valer o direito aos bens básicos e indispensáveis de consumo humano diário. A equidade, ou seja, o reconhecimento de necessidades diferentes, de sujeitos também diferentes, para alcançar direitos iguais, é o caminho da ética aplicada para a realização dos direitos humanos universais, entre eles o direito a uma vida digna. A equidade é um referencial que permite resolver parte razoável das distorções com relação à justiça distributiva, ao ampliar as possibilidades de vida de expressivos setores da população alijados dos bens mínimos para sua sobrevivência.

Segundo o poeta gaúcho, já falecido, Mário Quintana, democracia significa dar o mesmo ponto de partida para todos; o ponto de chegada depende de cada um... Neste sentido, o conceito de equidade aqui debatido diz respeito a que o Estado proporcione mecanismos compensatórios para os menos aquinhoados historicamente - como, por exemplo, a criação de cotas para ingresso de pessoas negras já utilizadas em diversas 
universidades públicas brasileiras - de modo que estas tenham o mesmo ponto de partida dos demais (igualdade) para concorrer de modo justo na busca de melhores condições de sobrevivência e vida.

0 tema do ambiente como propriedade de todos é um exemplo da relação existente entre o princípio da justiça em bioética, a equidade e a dimensão social. Deve-se garantir para todos os seres humanos: a) os direitos de primeira geração, relacionados ao reconhecimento da condição de pessoa como requisito universal e exclusivo para a titularidade de direitos; b) os direitos de segunda geração, que significam o reconhecimento dos direitos econômicos e sociais que se manifestam na dimensão material da existência; e c) os direitos de terceira geração, que se referem principalmente à relação com o ambiente e a preservação dos recursos naturais (GARRAFA ; PORTO, 2008).

No que se refere à questão ambiental, é indispensável a preservação e a manutenção dos recursos naturais para as gerações futuras, apontando a necessidade de superação do paradigma antropocêntrico e evidenciando que a ideia positivista de desenvolvimento a qualquer custo necessita ser urgentemente substituída pelo parâmetro da sustentabilidade. A dimensão ambiental se reproduz do mesmo modo observado na perspectiva pessoal com relação ao processo saúde-doença. Assim, como a saúde é percebida muitas vezes somente com o surgimento da doença, a importância da preservação do ambiente é avaliada quando se evidencia a escassez e falta de recursos necessários à própria vida.

Neste sentido, a incorporação dos chamados "direitos difusos" relacionados ao ambiente, nos referenciais teóricos da bioética, se configura como um imperativo categórico que determina a reavaliação de prioridades e a redução do consumo necessário à vida de pessoas e populações. Tal redução afeta a todos os Estados-nação, mas configura a assimetria entre diferentes países - e também entre cidadãos - uma vez que os segmentos mais ricos são exatamente aqueles que mais consomem e desperdiçam. É injustificável, hoje em dia, que as pessoas de alguns países, como Estados Unidos, tenham um consumo per capita diário de água ou petróleo - recursos naturais planetários que são finitos e que deveriam ser propriedade de todos - muitas vezes maior do que outros; 
ou que outras nações, como China e outra vez Estados Unidos, emitam para a atmosfera uma quantidade insuportável de gazes nocivos, absolutamente desproporcionada com relação aos demais.

A precaução com o meio ambiente necessita ser tratada não somente no sentido de preservação da biodiversidade, mas também com relação ao exercício da prudência frente a intervenções com consequências inseguras e/ou desconhecidas à sobrevivência humana e do planeta. Estas ações fazem parte do complexo contexto da ação preventiva que pode ser irradiada do princípio da justiça em uma bioética contemporânea, respeitosa e inclusiva frente aos direitos das gerações futuras a um ambiente puro, saudável e permanente.

\section{A DIMENSÃO POLÍTICA DO PRINCÍPIO DA JUSTIÇA}

O sentido clássico de política se origina do grego pólis, que significa tudo aquilo que se refere à cidade e, consequentemente, o que é urbano, civil, público e até sociável e social. Na época moderna o termo perdeu o significado original, passando a ser usado para indicar a atividade ou conjunto de atividades que, de algum modo, têm como referência o Estado. Derivado deste conceito, a pólis é, por vezes, sujeito quando se refere a atos políticos, como, por exemplo, o fato de retirar e transferir recursos de um setor da sociedade para outro; ou objeto, quando se refere a ações políticas, como a defesa nacional ou as conquistas de territórios (BOBBIO; MATTEUCCI; PASQUINO, 2004).

O conceito de política entendido como forma de atividade humana está estreitamente relacionado com o poder. A etimologia da palavra "poder" aponta sua origem do latim "potere", que significa deliberar, mandar, autoridade, soberania, influência ou força. 0 poder é definido também como uma relação entre dois sujeitos, onde um impõe sua vontade ao outro, determinando o comportamento (GARRAFA; MANCHOLA-CASTILLO; 2016). Como o domínio sobre os homens não é geralmente um fim em si mesmo, o poder como tipo de relação necessita ser complementado com a definição de poder como posse dos meios que permitem com que sejam alcançados os efeitos desejados. 
O que caracteriza o poder político é a exclusividade do uso da força com relação à totalidade de grupos que atuam em determinado contexto social (BOBBIO; MATTEUCCI; PASQUINO, 2004). Tal exclusividade, por sua vez, é resultado de um processo que se desenvolve em toda sociedade organizada, no sentido da monopolização da posse e uso dos meios com que se pode exercer a coação física.

Para Galbraith (1989), poder é a capacidade de alguém impor sua vontade sobre o comportamento de outras pessoas. Segundo Corrêa (1977), ele é uma força que exerce influência na conduta das pessoas. Para Aguiar (1983), é a capacidade de exercer influência interpessoal. Diferentes autores, contudo, definem o poder de um modo geral como o exercício da influência de uma pessoa sobre a outra.

0 conceito de poder vai muito além do poder político imposto pelo Estado, pois em cada esfera da organização estatal e social o poder está presente de forma complexa e de maneira interpessoal. E é aqui, precisamente, que entra a noção de cidadania. Por ser a cidadania algo construído e conquistado diariamente, o objetivo primordial é alcançá-la por meio da liberdade de consciência, da vontade de participar do processo de construção de uma nação. Para isto é necessária uma mudança de postura e ter conhecimento dos direitos à vida, à liberdade, à propriedade, à igualdade de direitos, enfim, direitos civis, políticos e sociais, e ter responsabilidades em prol do bem comum.

Como afirmou Arendt (2010), os indivíduos devem ser tratados iguais perante a lei, quando pertencentes a uma sociedade organizada. Para que haja um processo efetivo de transformação do sujeito comum para o sujeito com direitos - cidadão - se faz necessária uma educação direcionada para esta construção, visando a compreensão deste cidadão sobre a política, a dinâmica social, a educação, a saúde e todo o contexto de sua comunidade e Estado, tendo como objetivo final o empoderamento (SEN, 2000).

A expressão empowerment, tal como é entendida nos dias atuais, adquiriu visibilidade a partir da Inglaterra nos anos de 1970, com a chegada do desenvolvimento e modernização. Parte da ideia de dar poder a alguém, isto é, de dar liberdade e informação para que o indivíduo possa participar da vida social, de forma a descentralizar o poder. $\mathrm{Na}$ 
visão anglo-saxônica, o empoderamento está voltado para a mudança de posições de grupos vulneráveis por meio do empower, que traduzido para o português quer dizer autorizar, habilitar, permitir.

$\mathrm{Na}$ linha de pensamento acima assinalada, a ideia de empoderamento dos sujeitos individuais, vulnerados em consequência do processo histórico e das características culturais das sociedades nas quais estão inseridos, atravessa o todo social, interatuando como elemento capaz de amplificar vozes dos segmentos alijados do poder de decisão e promovendo sua inserção social.

Assim, parece claro que a ideia de empoderamento reporta justamente à importância de perceber que as escolhas dos sujeitos sociais não podem ser marcadas somente por uma visão míope e estereotipada de autonomia, que circunscreve a opção individual a um exercício narcisista e antropocêntrico, levando o pensamento em direção à questão de poder de uns e outros cidadãos em mundos desiguais. E, se a desigualdade é construída no meio social - na formação do indivíduo - suplantá-la implica em reconhecer a relação inequívoca entre autonomia e responsabilidade.

A autonomia se manifesta não somente na capacidade de contestar a uma situação de modo a atender ao mesmo tempo a moralidade social, as normas legais e necessidades e desejos do indivíduo, como também no reconhecimento da interconexão constatada entre os seres humanos e todas as formas de vida, bem como na responsabilidade existencial exigida frente a elas.

As ideias de Sen (2002), a respeito de empoderamento podem ser comparadas, por proximidade, com as do educador brasileiro Paulo Freire (2001), quando este fala de libertação. Guardadas as peculiaridades de cada uma das expressões e sua aplicação a diferentes contextos, Sen (2002), expressa com o uso da categoria empoderamento aquilo que Freire denomina libertação.

No entanto, essa concepção de libertação implica em mais do que o simples reconhecimento da existência de poder. Ela, necessariamente, aponta para o lócus onde se instalam as forças capazes de obrigar os indivíduos à sujeição e à fragilidade, manifesta na incapacidade de desvencilhar-se da submissão. Ao definir estes lócus, Freire identifica a oposição entre cativeiro - ou a privação do direito de escolha - e a 
libertação, o verdadeiro exercício da autonomia (FREIRE, 2001). Desta maneira, assinala que os sujeitos sociais são eminentemente atores políticos cuja ação pode tanto manter quanto transformar o status quo. A categoria teórica aqui desenvolvida - a libertação - desvela as posições de poder e permite pressupor uma tomada de posições no jogo de forças pela inclusão social.

A utilização da libertação em bioética possibilita indicar em qual direção deve ser conduzida a luta política para garantir tal liberdade. Sua adoção dá mais visibilidade à luta de cidadãos e cidadãs que alcançam sua inclusão social, seja no contexto da saúde e qualidade de vida, seja em contextos mais amplos, a partir da tomada de consciência sobre as forças que os oprimem e pela ação concreta em oposição a elas. Freire (2001), é particularmente contundente ao criticar o preciosismo acadêmico e sua malvada consequência - a assepsia moral - que constituem obstáculos para a libertação, ao afirmar que não tem nenhum interesse em assumir um ar de observador "acinzentado" e imparcial, além de reafirmar sua posição afirmativa e rigorosamente ética em defensa dos excluídos, dos "condenados da terra".

Mas, é indispensável registrar que ao contrário da expressão libertação, pouco utilizada no sentido aqui resgatado, a palavra empoderamento tem sua utilização mais aceita internacionalmente e incorporada aos léxicos sociais, jurídicos e mesmo sanitários em quase todo o mundo, mesmo na América Latina onde Freire é particularmente reconhecido. Entre outros motivos, se deve reconhecer a seguinte diferença: enquanto Freire se debatia em meio a teorias educacionais, de menor apelo mercantil imediato, Sen tem seu trabalho direcionado à área de Economia, de grande visibilidade no contexto capitalista. Embora os dois autores tenham desenvolvido seus estudos rigorosamente no mesmo sentido de favorecer as populações marginadas do planeta, o apelo à economia é flagrantemente maior que à educação no atual momento histórico pelo qual passa a humanidade.

À ideia de libertação pode ser somada a de emancipação, que a complementa e enriquece. 0 sujeito emancipado não deixa de ser uma pessoa livre. 0 sujeito emancipado, por exemplo, é aquele que adquiriu condição de maioridade e então começa a ser soberano e responsável 
pelas suas próprias ações. Emancipação significa franquia, independência, liberdade, o caminhar com as próprias pernas que se inicia com a libertação. Somente é emancipado aquele que logrou suprimir sua dependência, que alcançou o domínio sobre si próprio e pode garantir não somente a sobrevivência, mas principalmente suas livres escolhas frente aos meios de alcançar essa sobrevivência.

O poder sobre si próprio é o que outorga a emancipação, tornando a pessoa imune às forças que buscam sua sujeição. Portanto, suprimir a dependência é pré-condição para a emancipação e isso vale tanto para a pessoa como para o Estado. É com esta concepção que a categoria "emancipação" se presta à bioética e especificamente ao estudo da justiça, ou seja, como ferramenta ou veículo para direcionar a luta pela libertação, incluindo esta luta na sua dimensão coletiva.

Por outro lado, a emancipação parece ter um sentido mais jurídico que sociopolítico, sublinhando o reconhecimento legal da capacidade que uma pessoa tem para decidir. Todavia, para que a inclusão social (inerente ao cidadão emancipado) seja reflexo efetivo da autonomia, deve ser fruto de uma conquista pelo direito a decidir e pela possibilidade real do exercício deste direito. Não pode ser consequência de mera concessão, como um presente oferecido sem luta e que, por essa razão, igualmente, pode ser retirado em qualquer momento ou tempo ao sabor dos desejos daqueles que concederam a dádiva.

Para a construção de uma bioética pública e cidadã, a inclusão social significa a ação cotidiana de pessoas concretas e necessita ser trabalhada também na sua dimensão política, como um processo no qual os sujeitos livres e autônomos articulam suas ações. Na medida em que as ações cotidianas orientam as escolhas não somente em função de desejos pessoais, mas considerando as dimensões da totalidade concreta - a necessidade de garantir a existência das pessoas e de todas formas de vida planetária - ela se torna inclusiva, tendendo, em conseqüência, a oferecer uma maior simetria.

De todo modo, a utilização de qualquer das três expressões acima analisadas, no contexto da bioética e sua relação com o Princípio da Justiça - empoderamento, libertação e emancipação - não obstante suas conotações diversas, pode contribuir para uma melhor compreensão da 
dimensão política do princípio da justiça em bioética, como um processo dinâmico que necessita ser construído e levado à prática, objetivando o estabelecimento da verdadeira justiça social.

\section{CONSIDERAÇÕES FINAIS}

O campo abarcado pelo princípio da justiça, no contexto da bioética, é amplo e complexo. Escolher os ângulos mais adequados para estudar o tema não é tarefa fácil, pelo contrário. Menos ainda quando se trata do desafio de expor assunto de tamanha amplitude em um espaço relativamente exíguo.

A ideia central que conduziu nosso raciocínio foi o antecedente que - sendo a bioética um território inter e transdisciplinar do conhecimento, além de originalmente laica e comprometida com o respeito à pluralidade moral de pessoas e povos - seria necessária uma abordagem epistemológica da justiça em bioética capaz de proporcionar da melhor forma possível todos estes ingredientes. Neste sentido, decidimos por trabalhar a construção do tema a partir de uma releitura crítica, social e política, da justiça.

Os elementos básicos da presente explanação foram fixados, inicialmente, a partir da relação existente e hoje consolidada entre a bioética e os direitos humanos, ambos oxigenados de modo decisivo pelo princípio da justiça. Em seguida, se trabalhou o contexto da ampliação substantiva verificada na temática e agenda da bioética neste século XXI, depois da homologação da Declaração Universal sobre Bioética e Direitos Humanos da UNESCO, em 2005, com uma evidente politização da mesma, o que compromete ainda mais as decisões tomadas em seu nome.

$\mathrm{O}$ direito a uma vida digna para todas as pessoas acompanhou a apresentação das ideias, buscando uma harmonia temática e incluindo discussões sobre as relações da ética com a política e o conceito de equidade, além de enfocar as relações de pessoas e países com o meio ambiente e sua relação dramática com a finitude dos recursos naturais da terra. Terminando, o texto trabalhou a dimensão política da justiça em bioética, a partir da definição de empoderamento, libertação e emancipação das pessoas e povos, temas diretamente relacionados tanto com o Princípio da Justiça como com os Direitos Humanos. 
Finalizando, não é demais reforçar que o trabalho da bioética não está dirigido preferencialmente ao tema dos limites, ou seja, daquelas coisas que podem ou não podem ser feitas, daquelas coisas que são corretas ou incorretas sob o prisma do princípio da justiça. 0 que importa para uma bioética justa, democrática e cidadã são as razões que justificam um dado juízo de valores e a aplicação correta das decisões.

\section{REFERÊNCIAS}

AGUIAR, Maria. Psicologia aplicada à administração. São Paulo: Atlas, 1983.

ARENDT, Hannah. A condição humana. 11. ed. São Paulo: Forense Jurídica, 2010.

BEAUCHAMP, Tom; CHILDRESS, James. Principles of biomedical ethics. New York/Oxford: Oxford University Press, 1979.

. Principles of biomedical ethics. 4. ed. New York/Oxford: Oxford University Press, 1994.

. Principles of biomedical ethics. 5. ed. New York/Oxford: Oxford University Press, 2002.

Principles of biomedical ethics. 6. ed. New York/Oxford: Oxford University Press, 2008.

Principles of biomedical ethics. 7. ed. New York/Oxford: Oxford University Press, 2012.

BOBBIO, Norberto; MATTEUCCI, Nicola; PASQUINO, Gianfranco. Dicionário de Política. Brasília, Editora Universidade de Brasília, 2004.

CLOUSER, Danner ; GERT, Bernard. A critique of principlism. J Med Phil, v. 15, p. 219-36, 1990.

CORRÊA, Joaquim. 0 exercício do poder na administração: análise do comportamento de grupos em conflito. Rio de Janeiro: Documentário, 1977. 
FREIRE, Paulo. Pedagogia da autonomia. São Paulo: Paz e Terra, 2001.

GALBRAITH, John. Anatomia do poder. 3. ed. São Paulo: Pioneira, 1989.

GARRAFA, Volnei; DINIZ, Débora; MATOS D. Bioethical language and its dialects and idioletcts. Cad Saúde Públ, v.15, n. 1, p. 35-42, 1999.

GARRAFA, Volnei; KOTTOW, Miguel; SAADA, Alya. (coord.). Bases conceituais da bioética - enfoque latinoamericano. São Paulo: Gaia / UNESCO, 2006.

GARRAFA, Volnei; OSELKA, Gabriel ; DINIZ, Débora (1997). Saúde pública, bioética e equidade. Bioética, v. 5, n. 1, p. 27-33, 1997. Disponível: http:// revistabioetica.cfm.org.br/index.php/revista_bioetica/article/view/361/462.

GARRAFA, Volnei; TEN HAVE, Henk . National Bioethics Council. A Brazilian Proposal. Journal Medical Ethics, v. 36, n. 2, p. 99-102, 2010.

GARRAFA, Volnei. Da bioética de princípios a uma bioética interventiva - crítica e socialmente comprometida. Bioética, v. 13, n. 1, p. 125-134, 2005. Disponível em: http://revistabioetica.cfm.org.br/index.php/revista_bioetica/article/ view/97/102.

GARRAFA, Volnei. Ética y política (verbete). In: Tealdi JC (dir). Diccionario latinoamericano de bioética. Bogotá; Universidad Nacional de Colombia/ UNESCO, p. 531-533, 2008.

GARRAFA, Volnei; PORTO, Dora. Bioética de intervención (verbete). In: Tealdi JC (dir.). Diccionario Latinoamericana de Bioética. Bogotá: Unibiblos/ Redbioética-Unesco, p. 161-164, 2008.

GARRAFA, Volnei; MANCHOLA-CASTILLO, Camilo. Bioética y asimetría (negativa) de poder: explotación, desigualdad y derechos humanos. Rev. Redbioética/ UNESCO, 13(1):66-75, 2016.

GARRAFA, Volnei. Bioética. In GIOVANELLA, L., et al. (org). Políticas e sistemas de saúde no Brasil. Rio de Janeiro: Editora FIOCRUZ. 2. ed., p. 741-758, 2012.

HOLM, Soren. Not just autonomy: the principles of American biomedical ethics. J Med Ethics, v. 21, p.332-338, 1995. 
JONAS, Hans. Il princípio responsabilità. Torino: Einaudi, 1990.

LEPARGNEUR, H. Força e fraqueza dos princípios da bioética. Revista Bioética, v.4 n. 2. 1996. Disponível em: http://revistabioetica.cfm.org.br/index.php/ revista_bioetica/article/view/407/370.

RAWLS, Jonh. Uma teoria de justiça. São Paulo: Martins Fontesm, 2002.

SEN, Amartya. Desenvolvimento como liberdade. São Paulo: Companhia das Letras, 2002.

THE BELMONT REPORT. Ethical principles and guidelines for the protection of human subjects of research. National Commission for the Protection of Human Subjects of Biomedical and Behavioral Research 1979. In: Reich WT, (Ed). Encyclopedia of Bioetchics. Revised edition. New York: Macmillan, p. 2767-73, 1978.

UNESCO (2005). Declaração Universal sobre Bioética e Direitos Humanos. Paris, 19 de outubro de 2005. Tradução brasileira sob responsabilidade da Cátedra UNESCO de Bioética da Universidade de Brasília. Disponível em: http:// www.bioetica.catedraunesco.unb.br Acesso em: 20 set. 2017.

Recebido em: 6-12-2017

Aprovado em: 26-1-2018

\section{Volnei Garrafa}

Pós-doutor e professor titular na Cátedra UNESCO e Programa de PósGraduação em Bioética (PPGBioética) da Universidade de Brasília (UnB), Brasil. E-mail: garrafavolnei@gmail.com.

Universidade de Brasília - UnB/ Cátedra UNESCO de Bioética UnB - Brasília, DF, 70910-900.

\section{Camilo Manchola-Castillo}

Doutor pela Cátedra UNESCO e Programa de Pós-Graduação em Bioética (PPGBioética) da Universidade de Brasília (UnB), Brasil. E-mail: camilomanchola@gmail.com

Universidade de Brasília - UnB

UnB - Brasília, DF, 70910-900. 